\title{
The Problem of Dispersed Knowledge in Corporate Management
}

\author{
Abbott Jason $\mathrm{H}^{*}$ \\ Abbott Jason H, Business Faculty, Higher Colleges of Technology, Sharjah Women's College University ,City Sharjah, P.O.Box 7946, Sharjah, United Arab Emirates
}

\begin{abstract}
"Knowledge" is progressively known as being of central significance to organizations in the contemporary knowledge society. Observed evidence demonstrates that gradually knowledge-based tasks are being conducted by teams of geographically dispersed actors between markets and companies. Furthermore, firms are increasingly employing dispersed teams, since one of the benefits of dispersed teams is the ability of its members to provide diverse knowledge and expertise. In spite of all this industry attention, not much understood about how to successfully cooperate to facilitate different types of knowledge-based tasks. The research on dispersed collaboration and knowledge management is young, the consequences of managing dispersed knowledge are less understood, and the field is still being mapped out.
\end{abstract}

\section{Keywords: \\ Knowledge; Dispersed knowledge; Corporate} management

\section{Introduction}

According to [1]"Knowledge" is progressively known as being of central significance to organizations in the contemporary knowledge society. Observed evidence demonstrates that gradually knowledgebased tasks are being conducted by teams of geographically dispersed actors between markets and companies. Furthermore, firms are increasingly employing dispersed teams, since one of the benefits of dispersed teams is the ability of its members to provide diverse knowledge and expertise [2]. In spite of all this industry attention regarding corporate management, not much understood about how to successfully cooperate to facilitate different types of knowledge-based tasks [1]. The research on dispersed collaboration and knowledge management is young, the consequences of managing dispersed knowledge are less understood, and the field is still being mapped out [3].

In the age of globalization and ever-changing markets, knowledge is always found to be dispersed [4]. Each agent in the market has a sum of knowledge and it is imperfect according to [5], it is imperfect because it is not complete and clear, argued that prices are typically the factor that is known and it acts as a gauge of what is known in the market. Still these actions are unspoken knowledge. With unspoken knowledge, people are not often aware of the knowledge they retain or how valuable it can be to others [4], Effective transfer of implicit knowledge usually necessitates extensive personal interaction and reliance. People usually are not fully conscious of the knowledge they are sharing through price signals, nor do they fully notice the knowledge that they use when they make a price choice. Nevertheless, this dispersed and implicit knowledge is not adequate in any organization. It is imperative for managers to be able to utilize this dispersed knowledge in a suitable method [3].

\section{The Problem of Dispersed Knowledge}

When a consumer find the prices for products and services have been set by the complex calculus that is the sum whole of the implicit knowledge residing within the market [5]. This perspective is prevalent among some economists such as Friedrich Hayek [6], Knowledge is not central in nature it has the propensity of dissipating. Hayek preached that the market is made of isolated decisions and dispersed rivalries [7].

Hayek's [6] research and analysis shows that globalization and virtualization are some of the major causes for the dispersion of knowledge in markets and companies. As companies grow and expand, their markets change and so do the teams working together. Every team in each geographic area has some amount of knowledge but it is not complete and this problem is known as dispersed knowledge and it can lead to organizational problems [6].

These organizational problems need to be controlled; organizational central planning is of major importance for any organization to be able to control them. Central planning must involve, gathering information from different areas and parts of the organization and assembling it into one central database [7]. Many organizations use Enterprise Resource Planning (ERP) systems to gather all of its informational resources in one location and grant access to all users of the system to the same database for organizational consistency [8].

Nevertheless, this is not easy and requires enormous planning and resources. There are large amounts of knowledge that needs to be collected by organizations, and this requires more resources [9], Therefore, the bigger the organization, the more the dispersed knowledge and more resources required for the collection of the dispersed knowledge. However, this is getting easier and faster with the proliferation of the World Wide Web and the increase in its speed and quality of service. In addition, many software and hardware developers are moving from stand-alone programs and application to fully online applications, which leads to faster, better and more efficient methods of collecting dispersed knowledge [10].

Minkler [5] identified hesitation as another driver by which knowledge dispersion causes management problems. Dispersed knowledge causes structural doubt within organizations; a strong form of doubt exists when a decision-maker cannot specify all relevant alternatives or outcomes. There, three different types of doubtrelated decision situations are eminent: deterministic, stochastic, and

*Corresponding author: Abbott Jason $\mathrm{H}$,Business Faculty, Higher Colleges of Technology, Sharjah Women's CollegeUniversity, City Sharjah, P.O.Box 7946, Sharjah, United Arab Emirates, Tel: 971505072291; E-mail: abbottjharon@gmail.com

Recieved December 05, 2014; Accepted September 25, 2015; Published October 09, 2015

Citation: Abbott Jason H (2015) The Problem of Dispersed Knowledge in Corporate Management. J Entrepren Organiz Manag 4: 150. doi:10.4172/2169026X.1000150

Copyright: @ 2015 Abbott Jason H. This is an open-access article distributed under the terms of the Creative Commons Attribution License, which permits unrestricted use, distribution, and reproduction in any medium, provided the original author and source are credited. 
vague situations. Though the first two types are familiar, vagueness is less familiar Minkler argues, although in a stochastic situation the likelihoods of uncertain events are known, under vagueness only a probability distribution for the apparent frequencies is know. Uncertainty therefore results from the doubt associated with specifying which of a set of distributions is appropriate in a given situation [3]. Ambiguity is a prevalent element of real world decision making [11]. Although there is no agreement yet amongst economists about the suitable modeling of ambiguity, applying the concept of ambiguity to the analysis has already produced new and useful insights into many economic phenomena [7]. Therefore, if the problem of dispersion of knowledge is resolved, it can automatically resolve the problem of ambiguity [12].

\section{Conclusion}

After examining information about dispersed knowledge and its problems in markets and companies, we observed that dispersed knowledge could not help organizations achieve their operational objectives. The knowledge needs to be gathered and organized, subsequently it will provide complete information and help management and employees in improving the decision making and planning process. Managers need to understand that collecting dispersed knowledge will help them to understand the various strategies followed by different managers and executives in other parts of the world in and outside their organizational structure. This does not mean that the same strategies must be followed; nonetheless, they can be exploited in understanding the diversity and complexity of global business.

- Some have argued that getting the right knowledge in order to make decisions is not just a question of increasing the existing information and knowledge. It is imperative to have effective communication, integration of cognitive structures, and develop understanding. Therefore, it can be concluded that not only access to disperse knowledge and integration of information is important; nevertheless, it needs to be understood and employed in an efficient fashion.

\section{Refernces}

1. Assudani RH (2009) Dispersed Knowledge Work - Implications for Knowledge Intensive Firms. Journal of Knowledge Management 13: 521-532.

2. Becker MC (2001) Managing Dispersed Knowledge: Organizational Problems, Managerial Strategies, and Their Effectiveness. Journal of Management Studies 38: 1037-1051.

3. Raab KJ, Ambos B, Tallman S (2014) Strong or Invisible Hands? -Manageria Involvement in the Knowledge Sharing Process of Globally Dispersed Knowledge Groups. Journal of World Business 49: 32-41.

4. Cowen T, Parker D (1997) Markets in the Firm: A Market-Process Approach to Management. London, Great Britain: The Institute of Economic Affairs 1-10.

5. Minkler AP (1993) The Problem with Dispersed Knowledge: KYKLOS 46: 569587.

6. Khalil EL (2002) Information, Knowledge and the Close of Friedrich Hayek's System. Eastern Economic Journal 28: 319-340.

7. Sole D, Edmondson A (2002) Situated Knowledge and Learning in Dispersed Teams. British Journal of Management 13: S17-S34.

8. Goswami NS (2009) Dispersed knowledge centres - A New Paradigm for the pharmaceutical industry. Business Strategy Series10:209 - 220.

9. Mehrjerdi $Y Z$ (2010) Enterprise resource planning: risk and benefit analysis Business StrategySeries 11: 308-324.

10. Cramton CD (2001) The Mutual knowledge problem and its Consequences for DispersedCollaboration. Organization Science 12: 346-371.

11. Dew N, Velamuri SR, Venkataraman S (2004) Dispersed knowledge and an entrepreneurial theory of the Firm. Journal of Business Venturing 19: 659-679.

12. Corso M, Martini A, Pellegrini L, Massa S, Testa S (2006) Managing Dispersed Workers: The New Challenge in Knowledge Management. Technovation 26 583-594. 